\title{
Quantifying antibiotic use in paediatrics: a proposal for neonatal DDDs
}

\author{
T. B. Y. Liem • E. R. Heerdink • A. C. G. Egberts • \\ C. M. A. Rademaker
}

Received: 10 February 2010 / Accepted: 29 May 2010/Published online: 18 June 2010

(C) The Author(s) 2010. This article is published with open access at Springerlink.com

\begin{abstract}
The defined daily dose (DDD) as defined by the World Health Organization (WHO) has been the most frequently used unit of measurement to measure antibiotic use. However, measuring antibiotic use in paediatrics is a problem as the WHO DDD methodology is not applicable in children (aged $>1$ month) due to the large variation in body weight within this population. Based on the narrow range of body weights in the neonatal population, we therefore aimed to develop a set of neonatal DDDs for antibiotics. Eight wellrespected (inter)national sources for dosage recommendations of antibiotics in children and neonates were consulted for the assumed maintenance dose of the ten most frequently used antibiotics in neonatal intensive care units in its main indication for neonates. A set of neonatal DDDs for ten commonly used antibiotics in neonates based on an assumed neonatal weight of $2 \mathrm{~kg}$ was proposed. Primarily in children DDDs are not applicable to quantify antibiotic use since there is large variation in body weight. In the neonatal population, however, based on its narrow range of body weights and when
\end{abstract}

\footnotetext{
T. B. Y. Liem $(\bowtie) \cdot$ C. M. A. Rademaker

Department of Clinical Pharmacy,

Wilhelmina Children's Hospital,

University Medical Centre Utrecht,

Lundlaan 6, Room Ke.03.136.0,

3584 EA Utrecht, The Netherlands

e-mail: y.liem@umcutrecht.nl

E. R. Heerdink

Division of Pharmacoepidemiology \& Pharmacotherapy,

Utrecht Institute for Pharmaceutical Sciences,

Faculty of Science, Utrecht University,

Utrecht, The Netherlands

\section{A. C. G. Egberts}

Department of Clinical Pharmacy,

University Medical Centre Utrecht,

Utrecht, The Netherlands
}

access to patient level data is not available, neonatal DDDs can be used as a unit of measurement.

Detailed quantitative and qualitative knowledge of antibiotic use is essential to implement strategies for reducing overuse, underuse and misuse of antibiotics in order to address the threat posed by resistant microorganisms. Antibiotic use in hospitals can be quantified using several methods. The defined daily dose (DDD) as assigned by the World Health Organization (WHO) has been the most commonly used unit of measurement to quantify (e.g. as the number of DDDs used per 100 hospital days) in various settings and is particularly recommended to compare drug use between (international) settings, and has it shown its value for this purpose $[1,2]$. The DDD is the assumed average maintenance dose per day for a drug in its main indication for adults and is commonly expressed with a certain population size denominator such as patient days, bed days, admission days, inhabitant days. The popularity of the DDD mainly originates from its general applicability and its advantage that comparison of the amount of drug use between different (international) settings and between different drugs based on grouped dispensing data is possible without requiring utilization data on the individual patient level. The main disadvantage is that the DDD neither reflects the recommended, nor the actual prescribed daily dosage (PDD) for individual patients or specific patient populations [3-7]. Hence, in an ideal situation, the actual consumption of antibiotics should be measured at the level of the individual patient and subsequently aggregated over patient groups and settings. This gives more precise estimates but more importantly also allows study of associations on an individual patient level between patient characteristics, setting characteristics (e.g. antibi- 
otic policy), antibiotic use and clinically relevant outcomes, including antibiotic resistance [4].

One of the other main shortcomings of the DDD methodology is its applicability in paediatrics. In an editorial commentary, Monnet concluded that in addition to the revision of WHO DDD, more research is needed to address other problems, such as the difficulty in measuring antibiotic use in children in those hospitals where data at patient level are not available [5]. Problems arise because dosing of antibiotics in children is based on body weight. Therefore, in order to calculate a paediatric DDD, an average body weight for the paediatric population needs to be assumed. However, in our opinion, this methodology is questionable as there is a large variation in body weight within the paediatric population. This view is supported by the WHO International Working Group for Drug Statistics Methodology's publication 'Guidelines for ATC classification and DDD assignment' [8]. In this, the WHO states that it is impossible to define paediatric DDDs because dose recommendations for use in children vary according to age and body weight (and setting). Furthermore, many drugs used in paediatrics are not even approved for such use and dosing information is not available. In response to the WHOs negative comments about paediatric DDDs, several alternative measurement systems for antibiotic use in children have been proposed, e.g. an estimation of antibiotic exposure by controlling for patient weight and amount of wasted drug $[9,10]$.

Nevertheless, regarding the issue on variation in body weight, one should distinguish children ( $>1$ month of age) from neonates $(<1$ month of age) as the variation in body weight in children (mean body weight at age 1 month is $4.2 \mathrm{~kg}$ [11]; mean body weight at age 17 years is $60 \mathrm{~kg}$ [12]) is larger compared to the neonatal population (mean body weight $2.1 \mathrm{~kg} \pm 1.0$, based on own data). Consequently, in our view the disadvantage of the DDD methodology in paediatrics is more relevant for children than for neonates. Therefore, we aimed to devise a set of neonatal DDDs for antibiotics. We consulted eight well-respected (inter)national sources for dosage recommendations of antibiotics in children and neonates for the assumed maintenance dose of the ten most frequently used antibiotics in NICUs in its main indication for neonates (i.e. neonatal sepsis) (Table 1) [13]. Considering these antibiotics we did not find discrepancies in the dosage recommendations between the various evaluated sources. In addition, this overview of assumed maintenance dosages was evaluated and approved by two external experts: a hospital pharmacist and a paediatrician-infectious disease specialist. As a result, we propose a set of neonatal DDDs for commonly used antibiotics in neonates based on an assumed neonatal weight of $2 \mathrm{~kg}$ (Table 1). Regarding these proposed neonatal DDDs, one should, however, take into account the general limitations of the DDD but also limitations specific

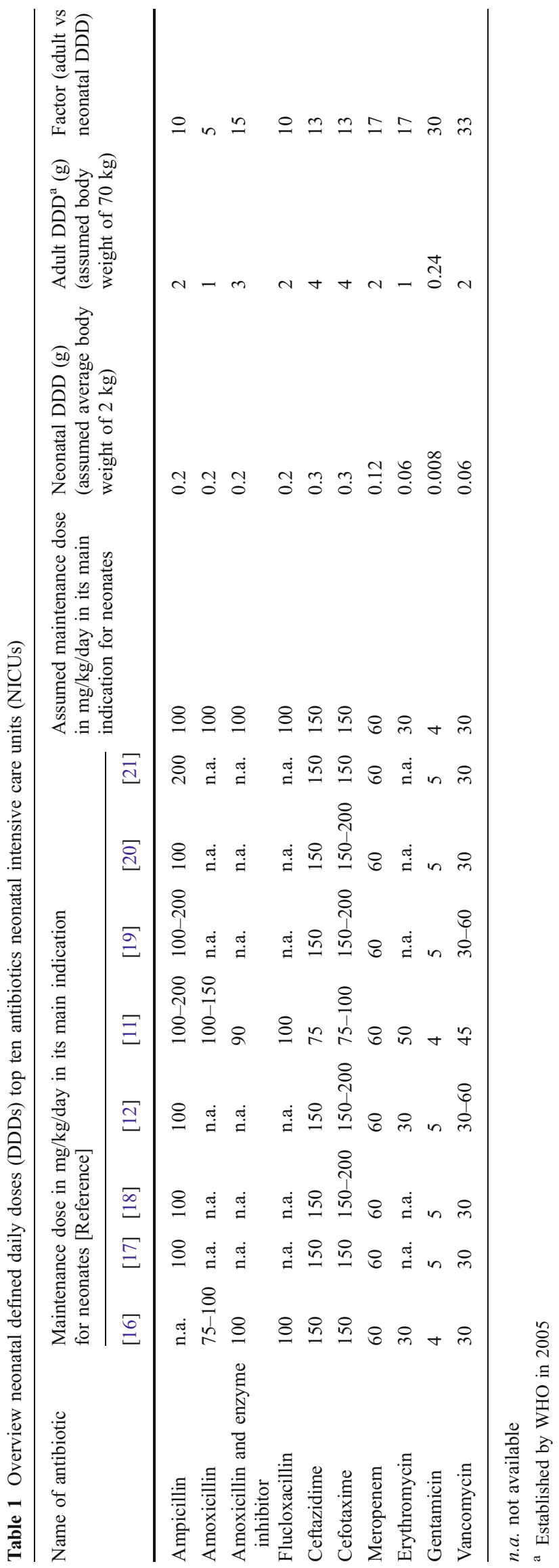


to this patient group such as the policy on handling of waste of unused antibiotics in a NICU setting. After all, waste of unused antibiotics would not reflect a real estimate of neonatal DDDs.

Obviously, our proposed neonatal DDDs do not alter the fact that there is a lack of data on antibiotic use on the individual patient level. Yet, with the increasing use of computerised medical information systems it will be considerably easier to get access to data on the level of the individual patient, such as days of therapy (DOT). DOT is not influenced by discrepancies between the DDD and the PDD, by changes in the WHO assigned DDD and is independent of age- and weight-related differences in dosage [7, 14]. A major disadvantage of this parameter is, however, that currently such detailed data on the individual patient level are not readily available. Moreover, if one would like to link data on antibiotic use to resistance, preferably both units of measurement, DOT (independent of dosage) and DDD (dependent of dosage), should be used, since it is unidentified which of these measurement methods is most predictive of resistance [7]. A recent study has shown that repeated and/or prolonged antibiotic use in neonates resulted in an increase of hospital-acquired, antibiotic-resistant organisms such as methicillin-resistant Staphylococcus aureus, vancomycin-resistant Enterococcus, and multidrug-resistant Gram-negative rods [15].

In conclusion, in order to quantify antibiotic use, the DDD methodology is not applicable in the paediatric population, mainly in children aged between 1 month and 18 years, due to the large variation in body weight within this population. Although, in the neonatal population, until patient level data are widely available and based on its narrow range of body weights, we suggest, illustrated by the example of antibiotics, that the neonatal DDD (nDDD) is a good alternative unit of measurement, both in research and for benchmarking purposes.

Acknowledgments We thank Dr. J. Zwaveling, hospital pharmacist, and Dr. T.F.W. Wolfs, paediatrician-infectious disease specialist, for evaluating and approving the overview of assumed maintenance dosages of antibiotics in neonates.

Open Access This article is distributed under the terms of the Creative Commons Attribution Noncommercial License which permits any noncommercial use, distribution, and reproduction in any medium, provided the original author(s) and source are credited.

\section{References}

1. Natsch S, Hekster YA, de Jong R, Heerdink ER, Herings RM, Van Der Meer JW (1998) Application of the ATC/DDD methodology to monitor antibiotic drug use. Eur J Clin Microbiol Infect Dis 17:20-24

2. World Health Organization (2002) Guidelines for ATC classification and DDD assignment. WHO Collaborating Centre for Drug Statistics Methodology, Norwegian Institute of Public Health, Oslo
3. Berrington A (2010) Antimicrobial prescribing in hospitals: be careful what you measure. J Antimicrob Chemother 65:163-168

4. De With K, Maier L, Steib-Bauert M, Kern P, Kern WV (2006) Trends in antibiotic use at a university hospital: defined or prescribed daily doses? Patient days or admissions as denominator? Infection 34:91-94

5. Monnet DL (2007) Measuring antimicrobial use: the way forward. Clin Infect Dis 44:671-673

6. Muller A, Monnet DL, Talon D, Henon T, Bertrand X (2006) Discrepancies between prescribed daily doses and WHO defined daily doses of antibacterials at a university hospital. Br J Clin Pharmacol 61:585-591

7. Polk RE, Fox C, Mahoney A, Letcavage J, MacDougall C (2007) Measurement of adult antibacterial drug use in 130 US hospitals: comparison of defined daily dose and days of therapy. Clin Infect Dis 44:664-670

8. World Health Organization (2008) Guidelines for ATC classification and DDD assignment 2009. WHO Collaborating Centre for Drug Statistics Methodology, Norwegian Institute of Public Health, Oslo

9. Antachopoulos C (2004) Development of a paediatric daily defined dose system for the measurement of antibiotic consumption in paediatric units. Presented at: The 14th European Congress of clinical microbiology and infectious diseases,Prague, Czech Republic, May 1-4, 2004

10. Bennet R, Eriksson M, Fant H (2006) Estimating exposure to antimicrobial agents in a pediatric hospital ward, controlling for patient weight and waste of unused drug [abstract K-1413]. In: Abstracts of the 46th Interscience conference on antimicrobial agents and chemotherapy (San Francisco). American Society for Microbiology, Washington, pp 345

11. Paediatric Formulary Committee (2009) BNF for children 2009. BMJ Group, RPS Publishing and RCPCH Publications, London

12. Taketomo CK, Hodding JH, Kraus DM (2008) Pediatric dosage handbook, 15th edn. Lexi-Comp, Hudson, Ohio, USA

13. Liem TB, Krediet TG, Fleer A, Egberts TC, Rademaker CM (2010) Variation in antibiotic use in neonatal intensive care units in the Netherlands. J Antimicrob Chemother 65(6):1270-1275

14. Pakyz AL, Gurgle HE, Ibrahim OM, Oinonen MJ, Polk RE (2009) Trends in antibacterial use in hospitalized pediatric patients in United States academic health centers. Infect Control Hosp Epidemiol 30:600-603

15. Bizzarro MJ, Gallagher PG (2007) Antibiotic-resistant organisms in the neonatal intensive care unit. Semin Perinatol 31:26-32

16. Nederlands Kenniscentrum voor Farmacotherapie bij Kinderen (NKFK) (2010) Het Kinderformularium. www.kinderformularium.nl. Accessed 11 June 2010

17. Sáez-Llorens X, McCracken GH Jr (2006) Clinical pharmacology of antibacterial agents. In: Remington JS, Klein JO, Wilson CB, Baker CJ (eds) Infectious diseases of the fetus and the newborn infant, 6th ed. Elsevier Saunders, Philadelphia, pp 1223-1267

18. James LP, Abdel-Rahman S, Farrar HC, Jacobs RF (2003) Antimicrobial agents. In: Long SS, Pickering LK, Prober CG (eds) Principles and practices of pediatric infectious diseases, 2nd ed. Churchill Livingstone, Amsterdam, pp 1458-1510

19. Rennels MB, Frenck RW, Baker CJ, Long SS, Baltimore R, McMillan JA (2006) Red book. American Academy of Pediatrics, Elk Grove Village, IL, USA

20. Michelow IC, McCracken GH Jr (2004) Antimicrobial therapeutic agents. In: Feigin RD, Cherry JD, Demmler GJ, Kaplan SL (eds) Textbook of pediatric infectious diseases, 5th ed. Elsevier Saunders, Amsterdam, pp 2987-3029

21. Bradley JS, Nelson JD (2009) Nelson's pocket book of pediatric antimicrobial therapy, 7th ed. Elk Grove Village, IL, USA 